УДК 314.154

$10.17213 / 2075-2067-2021-4-164-171$

\title{
ИСПОЛЬЗОВАНИЕ ЭКОНОМЕТРИЧЕСКИХ МОДЕЛЕЙ ДЛЯ ПРОГНОЗИРОВАНИЯ ДЕМОГРАФИЧЕСКОЙ СИТУАЦИИ В РФ
}

(C) 2021 г. Т. Г. Плеханова*, И. Б Жукова , Е. В. Плеханова

"Шахтинский автодорожнный институт (филиал), Южно-Российский государственный политехнический университет (НПИ) имени М. И. Платова, г. Шахты, Россия

** Донской государственный технический университет, г. Ростов-на-Дону, Россия

Целью исследования является обоснование направлений демографической политики в РФ с учетом выявленных факторов влияния на повышение рождаемости, например, размер материнского капитала и уровень средней заработной платы в регионе.

Методологическую базу исследования представляет теория демографического перехода, на основе которой применено эконометрическое моделирование, рассматривающее экономические условия в качестве основного фактора роста рождаемости. Применение этих методов и подходов позволяет выявить основные факторы влияния на демографический прочесс в зависимости от сложившейся экономической ситуации в регионе, определив основные характеристики этого распределения.

Результаты исследования. Одним из важных результатов является выявленный эффект слабой реакиии уровня рождаемости на растущий уровень доходов населения. Это обстоятельство говорит о незначительном росте доходов и диспропориии развития российской экономики, отражающейся в неравномерном региональном распределении доходов. Его применение вряд ли даст результат по формированию новой устойчивой модели демографического роста. Приходим к выводу, что рост рождаемости возможен при существенном повышении доходов населения. На сложившуюся модель роста уровня рождаемости в России оказывает влияние проводимая демографическая политика, но она не учитывает экономическое состояние населения и не влияет на него с иелью коренного изменения. Рассмотренные типовые варианты демографической модели роста учитывают указанные обстоятельства, но анализ показал слабое влияние фактора доходов населения.

Перспективу исследования составляет углубленный анализ других выявленных факторов, таких как доступность ипотеки и выбор конкретных инструментов демографической политики. Использованы данные Федеральной службы государственной статистики.

Ключевые слова: уровень рождаемости; численность населения; эконометрическая модель; факторы; материнский капитал; средняя заработная плата.

\section{USING ECONOMETRIC MODELS TO PREDICT THE DEMOGRAPHIC SITUATION IN THE RUSSIAN FEDERATION}

\author{
(C) 2021 T. G. Plekhanova*, I. B. Zhukova*, E. V. Plekhanova**
}

"Shakhty Road Institute (branch),

Platov South Russian State Polytechnic University (NPI), Shakhty, Russia

"Don State Technical University, Rostov-on-Don, Russia 
The purpose of the study is to substantiate the directions of demographic policy in the Russian Federation, taking into account the identified factors influencing the increase in the birth rate, for example, the size of the maternity capital and the level of average wages in the region.

The methodological basis of the study is the theory of demographic transition, on the basis of which econometric modeling is applied, considering economic conditions as the main factor of birth rate growth. The use of these methods and approaches allows us to identify the main factors influencing the demographic process, depending on the current economic situation in the region, identifying the main characteristics of this distribution.

The results of the study. One of the important results is the revealed effect of the weak response of the birth rate to the growing level of income of the population. This fact indicates a slight increase in income and a disparity in the development of the Russian economy, which is reflected in the uneven regional distribution of income, and its application is unlikely to result in the formation of a new sustainable model of demographic growth. We conclude that an increase in the birth rate is possible with a significant increase in the income of the population. The current growth model in Russia is influenced by the current demographic policy, but it does not take into account the economic condition of the population and does not affect them in order to radically change them. The considered standard variants of the demographic growth model take into account these circumstances, but the analysis showed a weak influence of the income factor of the population.

The perspective of the study is an in-depth analysis of other identified factors, such as the availability of mortgages and the choice of specific demographic policy tools.

Key words: birth rate; population size; econometric model; factors; maternity capital; average salary.

Введение. В Российской Федерации наблюдается снижение численности населения, причем в ближайшие годы эта тенденция будет расти. На 1.01.2020 г. численность населения составляет 146748590 человек, и РФ занимает девятое место в мире по данному показателю [3]. Многие страны наблюдают такую демографическую ситуацию, как изменение возрастной структуры населения, вызванное снижением роста рождаемости и увеличением продолжительности жизни, что приводит к уменьшению доли детей и трудоспособного населения, а удельный вес нетрудоспособного населения увеличивается. Это явление часто называют «демографическим старением». По данным Росстата, население России впервые за 15 лет снизилось более чем на 500 тыс. человек за прошедший год [2]. Вице-премьер России Татьяна Голикова назвала это явление «демографическим вызовом». Свое влияние оказала, конечно, пандемия, но тенденция к снижению численности наблюдается уже несколько лет. По прогнозам, сокращение численности населения в этом году составит поч- ти 352,5 тыс. человек, что в 11 раз превышает прошлогодние показатели. Для преодоления сложившейся ситуации в РФ разработана Концепция демографической политики. Направления деятельности для улучшения демографической ситуации определяют, в частности, факторы, влияющие на рождаемость. Задача данной работы - выделение и определение значимости этих факторов.

Тенденции демографической ситуации. Теория демографического перехода заявила о себе в 30-х годах XX столетия и связана работами А. Ландри [3], в которых сформулирована модель перехода. Эта модель находит подтверждение в работах исследователей отечественных ученых, таких как Н.Б. Баркалов, А.И. Антонов, А.Г. Волков, В.А. Борисов, Л.Е. Дарский. Эта теория определяет три стадии перехода: примитивную (высокая рождаемость и высокая смертность), промежуточную (высокая рождаемость и относительно низкая смертность) и современную (низкая рождаемость и низ- 
кая смертность, стабилизация численности населения) [3]. Можно заметить, что Россия находится примерно в третьей стадии перехода, но наблюдается значительное снижение численности населения.

Снижение рождаемости имеет ряд экономических последствий, влияющих на многие социальные процессы. Возросшая доля пенсионеров на фоне снижения рождаемости значительно увеличивает нагрузку на работоспособное население, приводит к перекосам на рынке занятости и даже к колебаниям числа абитуриентов в вузы.

Анализ демографической ситуации с позиции рождаемости в Российской Федерации. В годы перестройки численность населения РФ уменьшалась, а 2009 год стал переломным, уже 2013 и 2014 годы показали рост численности населения. В 2016 году рост составил почти 200 тыс. человек. В настоящее время убыль населения имеет соизмеримые значения. Немалую роль сыграла и «мода» на одного ребенка в семье, хотя раньше считалось абсолютно нормальным иметь в семье 2-3 ребенка.

Правительство РФ принимает различные меры по стабилизации численности населения, среди них такие как выплата материнского капитала и за первого ребенка, его ежегодная индексация, льготная ипотека для молодых семей, рост выплат на несовершеннолетних детей и многое другое. Для прогнозирования и моделирования выбрана Ростовская область, где наблюдается значительное снижение рождаемости с 2015 года. Так, снижение рождаемости в 2020 году составило более 10 тыс. чел.

Показатель рождаемости в Ростовской области приведен на рисунке 1, на котором заметно значительное снижение показателя с 2016 года.

Анализ факторов влияния на рождаемость и выбор переменных модели. Проанализируем факторы, оказывающие влияние на количество рожденных детей, с помощью эконометрической модели.

Для построения прогнозов демографической ситуации в стране используют различные виды моделей: дискретные, детерминистские макромодели одного или группы демографических процессов. Особенностью построения моделей этого типа является выбор эндогенных и экзогенных переменных. Так известно, эндогенные переменные формируются в модели, к ним можно отнести такие переменные, как численность населения, число рожденных детей, темпы изменения и т. Д. С другой стороны, экзогенные переменные определяются вне модели, по своему характеру они могут быть как демографическими, так и недемографическими, например, социально-психологическими, экономическими и т.п.

Определим состав переменных нашей модели, рассмотрим влияние различных социально-экономических факторов на рост рождае-

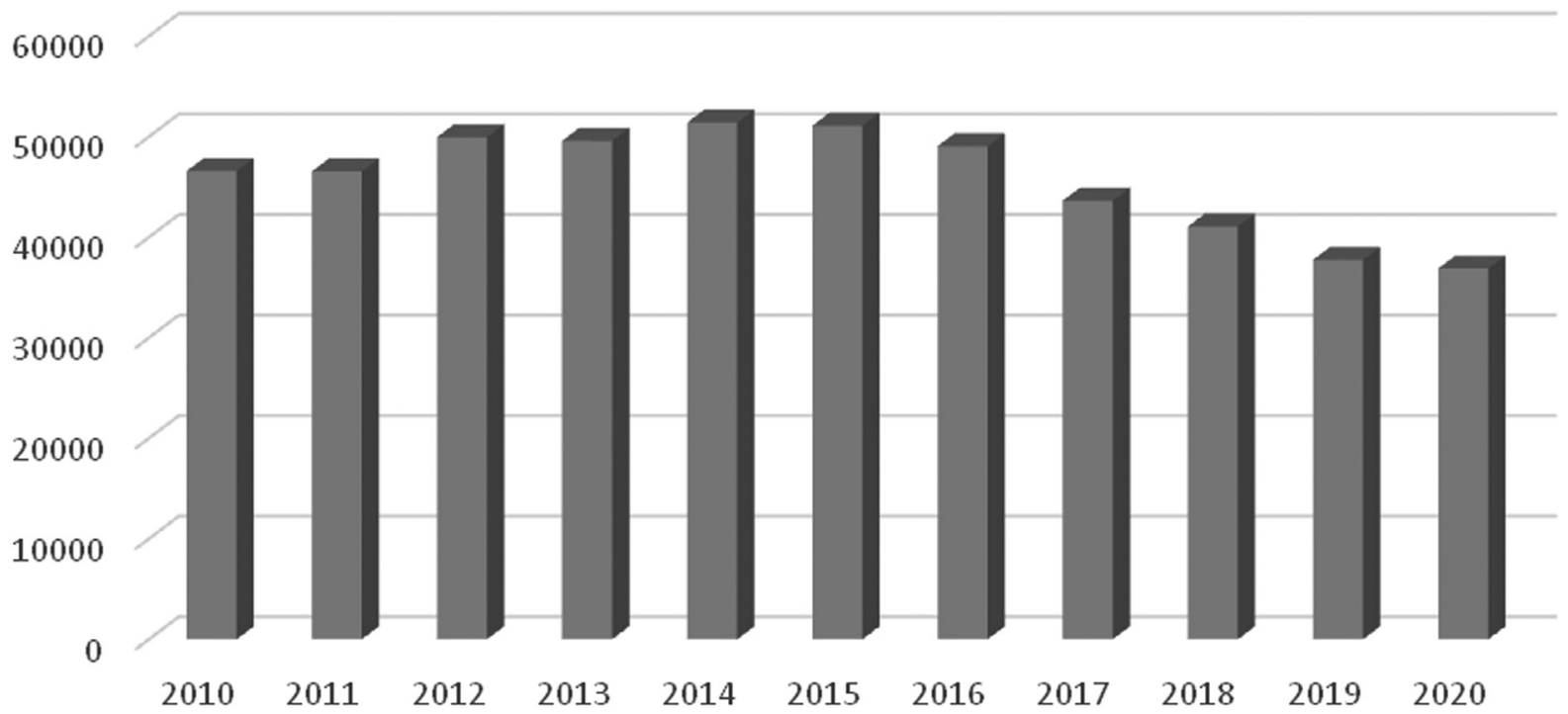

Рис. 1. Рождаемость в Ростовской области 2010-2020 гг. 
мости на примере Ростовской области. Попробуем определить влияние таких факторов, как размер материнского капитала и средняя заработная плата за последний период 20102020 гг. Данные статистики внесем в таблицу 1.

Для построения модели использовался пакет анализа в MS Excel. Результат расчета Rмнож $=0,706$, что говорит о верном выбо- ре эндогенных переменных, но влияние размера материнского капитала незначительно, а уровень средней заработной платы дает парадоксальный результат - отрицательное влияние. В настоящее время это демографическое явление можно наблюдать в европейских странах с высоким уровнем жизни, например, Швеции или Дании. По уровню

Статистические данные по Ростовской области

Таблица 1

\begin{tabular}{|c|c|c|c|}
\hline По годам & Рождаемость, чел. & Ср. зарплата, руб. & $\begin{array}{c}\text { Размер мат. капитала, } \\
\text { руб. (на 1 ребенка) }\end{array}$ \\
\hline 2010 & 46564 & 16430,6 & 343378 \\
\hline 2011 & 46519 & 18535,3 & 365698 \\
\hline 2012 & 49935 & 21358,3 & 387640 \\
\hline 2013 & 49569 & 24435,5 & 409026 \\
\hline 2014 & 51392 & 26679,1 & 429408 \\
\hline 2015 & 51081 & 27900,6 & 451000 \\
\hline 2016 & 49038 & 30008,1 & 471000 \\
\hline 2017 & 43614 & 28499,6 & 491000 \\
\hline 2018 & 41052 & 31448,2 & 453000 \\
\hline 2019 & 37730 & 33757,1 & 453026 \\
\hline 2020 & 36867 & 35699,7 & 466617 \\
\hline
\end{tabular}

Таблица 2

Расчет уровня рождаемости и оценка модели

\begin{tabular}{|c|c|c|c|c|c|}
\hline По годам & $\begin{array}{c}\text { Рождаемость, } \\
\text { чел. }\end{array}$ & $\begin{array}{c}\text { Ср. зарплата, } \\
\text { руб. }\end{array}$ & $\begin{array}{c}\text { Размер мат. } \\
\text { капитала, руб. }\end{array}$ & $\begin{array}{c}\text { Расчетное } \\
\text { значение }\end{array}$ & $\varepsilon$ \\
\hline 2010 & 46564 & 16430,6 & 343378 & 49670,73 & $-3106,73$ \\
\hline 2011 & 46519 & 18535,3 & 365698 & 49329,19 & $-2810,19$ \\
\hline 2012 & 49935 & 21358,3 & 387640 & 48132,77 & 1802,23 \\
\hline 2013 & 49569 & 24435,5 & 409026 & 46594,82 & 2974,18 \\
\hline 2014 & 51392 & 26679,1 & 429408 & 45915,76 & 5476,24 \\
\hline 2015 & 51081 & 27900,6 & 451000 & 46515,21 & 4565,79 \\
\hline 2016 & 49038 & 28499,6 & 471000 & 47678,27 & 1359,73 \\
\hline 2017 & 43614 & 30008,1 & 491000 & 47803,08 & $-4189,08$ \\
\hline 2018 & 41052 & 31448,2 & 453000 & 42650,13 & $-1598,13$ \\
\hline 2019 & 37730 & 33757,1 & 453026 & 40016,8 & $-2286,80$ \\
\hline 2020 & 36867 & 35699,7 & 466617 & 39054,25 & $-2187,25$ \\
\hline & & & & $\Sigma \varepsilon=$ & 0 \\
\hline
\end{tabular}




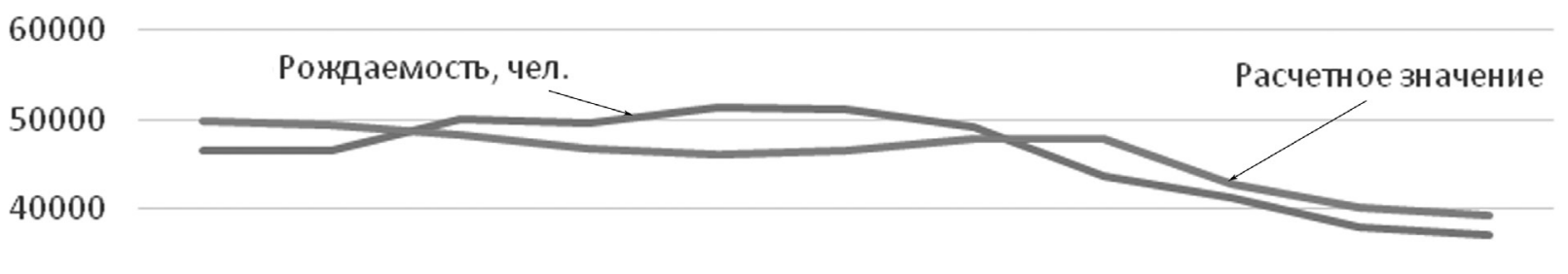

30000

20000

10000

0

\section{$\begin{array}{lllllllllll}2010 & 2011 & 2012 & 2013 & 2014 & 2015 & 2016 & 2017 & 2018 & 2019 & 2020\end{array}$}

Рис. 2. График соотношения статистических данных и прогнозируемых

жизни Дания занимает лидирующие позиции в мире. Бесплатное медицинское обслуживание определяет высокую продолжительность жизни: женщины живут до 80 лет, мужчины - до 75. Минимальная зарплата составляет 2500 евро в месяц. При перечисленных высоких показателях уровня жизни рождаемость составляет 10,9 чел. на 1000 человек населения, незначительный рост наблюдается только с 2015 года. Аналогичную картину можно наблюдать и в Швеции, где уже в 2020 году лица старше 65 лет должны составить $22 \%$ от населения Швеции. В России также наблюдается современная тенденция семей «childfree», молодежь стремится к карьерному росту и не обзаводится детьми, находясь в фертильном возрасте.

Результаты применения данной модели приведены в таблице 2. Данные и результаты расчетов отражены на рисунке 2. На графике видно, что предложенная модель достаточно точно отражает процессы в демографическом исследовании.

Заключение. Подобные модели можно применять для исследования факторов, влияющих на рост рождаемости как в регионе, так и масштабах страны. Трудность исследования заключается в том, что для полноты модели необходимо расширить набор переменных. В данной модели не использованы факторы наличия жилья или ипотеки. Перечисленные факторы носят качественный характер, что приводит к использованию регрессионных мо- делей, содержащих и качественные объясняющие переменные (модели ANOVA), и модели зависимой фиктивной переменной (модели LPM). Качественные признаки могут существенно влиять на структуру линейных связей и приводить к скачкообразному изменению параметров регрессионной модели. Затруднен также вопрос построения моделей по признаку роста рождаемости за счет увеличения детей в семье или рождения первого ребенка.

\section{Литература}

1. Концепция демографической политики Российской Федерации на период до 2025 года (утв. Указом Президента РФ от 9 октября 2007 г. №351).

2. Федеральная служба государственной статистики [Электронный ресурс]. Режим доступа: https://rosstat.gov.ru/folder/ 12781? print $=1$.

3. Аракчеева О.В., Кривдина И.Ю. Современная демографическая ситуация в Российской Федерации: региональный аспект// Успехи современного естествознания. 2020. — №11. - С. 39-40.

4. Чистова Е.В. Подход к определению стадии демографического старения населения на региональном уровне [Электронный pecypc]. — Режим доступа: https://elar.urfu.ru/ bitstream/10995/55771/1/8udf2_098.pdf.

5. Кабашова Е.В. Сравнительный анализ демографического старения населения в регионах Российской Федерации // Ученые 
записки Российского государственного социального университета. - 2013. - Т. 2. №6(122). - C. 22-27.

6. Landry A. La Révolution Démographique/ A. Landry, A. Girard. - INED, 1982. - 230 p.

7. Доброхлеб В.Г., Барсуков В.Н. Демографические теории и региональный аспект старения населения. Экономические и социальные перемены: факты, тенденции, прогно3. - 2017. - Т. 10. — №6. - С. 36-55.

8. Кабашова Е. В. Статистический анализ основных показателей и последствий демографического старения населения в Приволжском федеральном округе // Успехи современной науки и образования. - 2016. - Т. 3. №7. - С. 79-82.

9. Пухова А.Г., Беляева Т.К., Толкунова С.Г., Курбатова А.С. Влияние демографического фактора на региональный рынок труда [Электронный ресурс]. - Режим доступа: https:// voluntary.ru/termin/regionalnaja-demografija. html.

10. Сафарова Г.В. Демографические аспекты старения населения России. Отечественные записки. - 2005. - №3.

\section{References}

1. Koncepcija demograficheskoj politiki Rossijskoj Federacii na period do 2025 goda (utv. Ukazom Prezidenta RF ot 9 oktjabrja 2007 g. №351) [The Concept of Demographic Policy of the Russian Federation for the period up to 2025 (approved by Decree of the President of the Russian Federation №351 of October 9, 2007)].

2. Federal'naja sluzhba gosudarstvennoj statistiki [Federal State Statistics Service] [Jelektronnyj resurs]. — URL: https://rosstat.gov.ru/ folder/12781?print $=1$.

3. Arakcheeva O.V., Krivdina I. Ju. Sovremennaja demograficheskaja situacija v Rossijskoj Federacii: regional'nyj aspekt [The current demographic situation in the Russian Federation: a regional aspect] // Uspehi sovremennogo estestvoznanija [The successes of modern natural science]. — 2020. — №11. - Pp. 39-40.
4. Chistova E. V. Podhod k opredeleniju stadii demograficheskogo starenija naselenija na regional'nom urovne [Approach to determining the stage of demographic aging of the population at the regional level] [Jelektronnyj resurs]. - URL: https://elar.urfu.ru/bitstream/10995/55771/1/8udf2_098.pdf.

5. Kabashova E. V. Sravnitel'nyj analiz demograficheskogo starenija naselenija $\mathrm{v}$ regionah Rossijskoj Federacii [Comparative analysis of demographic aging of the population in the regions of the Russian Federation] // Uchenye zapiski Rossijskogo gosudarstvennogo social'nogo universiteta [Scientific notes of the Russian State Social University]. — 2013. - Vol. 2. №6 (122). - Pp. 22-27.

6. Landry A. La Révolution Démographique/ A. Landry, A. Girard. - INED, 1982. - 230 p.

7. Dobrohleb V.G., Barsukov V.N. Demograficheskie teorii i regional'nyj aspekt starenija naselenija. Jekonomicheskie i social'nye peremeny: fakty, tendencii, prognoz [Demographic theories and the regional aspect of population aging. Economic and social changes: facts, trends, forecast]. - 2017. - Vol. 10. — №6. - Pp. 36-55.

8. Kabashova E.V. Statisticheskij analiz osnovnyh pokazatelej i posledstvij demograficheskogo starenija naselenija v Privolzhskom federal'nom okruge [Statistical analysis of the main indicators and consequences of demographic aging of the population in the Volga Federal District] // Uspehi sovremennoj nauki i obrazovanija [Successes of modern science and education]. — 2016. — Vol. 3. - №7. Pp. 79-82.

9. Puhova A. G., Beljaeva T.K., Tolkunova S. G., Kurbatova A.S. Vlijanie demograficheskogo faktora na regional'nyj rynok truda [The influence of the demographic factor on the regional labor market] [Jelektronnyj resurs]. - URL: https://voluntary.ru/termin/regionalnaja-demografija.html.

10. Safarova G.V. Demograficheskie aspekty starenija naselenija Rossii. Otechestvennye zapiski [Demographic aspects of the aging of the Russian population. Domestic notes]. 2005. — №3. 


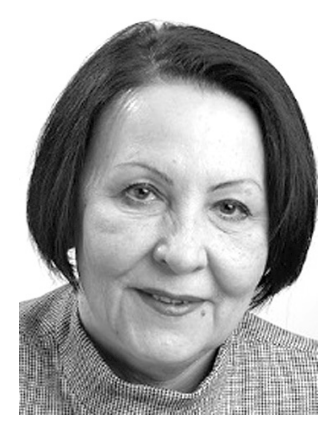

346504, г. Шахты, ул. Рылеева, 43б, кв. 13

43b Ryleeva st., app. 13, 346504, Shakhty, Russia

E-mail: ptgep@mail.ru

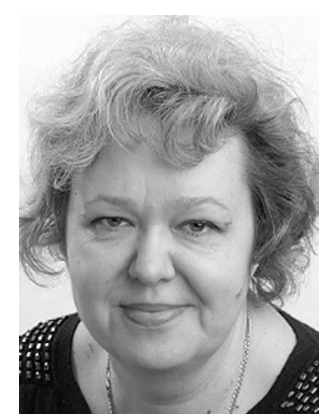

Жукова Ирина Борисовна - доцент, кандидат экономических наук, доцент кафедры «Экономика и управление» Шахтинского автодорожного института (филиала) Южно-Российского государственного политехнического университета (НПИ) имени М.И. Платова.

Zhukova Irina Borisovna - Associate Professor, Candidate of Economic Sciences, Associate Professor of the Department of Economics and management, Shakhty Road Institute (branch), Platov South Russian State Polytechnic University (NPI).

346500, г. Шахты, пер. Луговой, 12

12 Lugovoy st., app. 13, 346500, Shakhty, Russia

E-mail: zlynx@yandex.ru 


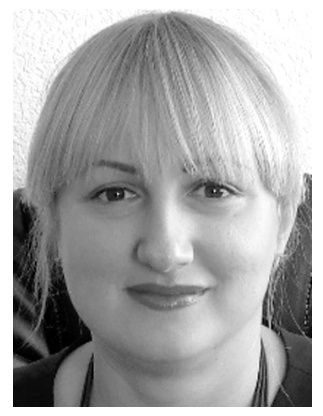

Плеханова Елизавета Валерьевна - доцент, кандидат химических наук, доцент кафедры «Химия» Донского государственного технического университета.

Plekhanova Elizaveta Valeryevna - Associate Professor, Candidate of Chemical Sciences, Associate Professor of the Department of Chemistry, Don State Technical University.

344403, г. Ростов-на-Дону, пер. Машиностроительный, 5, кв. 46 12 Mashinostroitelny ln., app.46, 344403, Rostov-on-Don, Russia

E-mail: plekhanova.elizaveta@yandex.ru 